Paulo Affonso Leme Machado, promotor de Justiça, mestre em direito ambiental e ordenamento territorial (Universidade de

Strasbourg, França). Professor de política e legislação ambiental do Instituto de Biociências da Unesp, presidente da Sociedade Brasileira de Direito do Meio Ambiente e autor da obra Direito ambiental brasileiro.

\title{
Sistema orgânico para gestão ambiental - proposta de um sistema adequado
}

\section{Introdução}

Serão tratadas nestas jornadas (Jornadas sobre Medio Ambiente y Ordenamiento Jurídico) diversas matérias que merecem ser mencionadas: o conceito de ambiente e seu enfoque sistêmico, o direito ambiental como disciplina jurídica, sociedade e direito ambiental, critérios e princípios de direito ambiental e instituições dessa disciplina jurídica.

Procuraremos não ser repetitivos, nem adentrar em assunto a ser abordado pelos anteriores conferencistas, inobstante ser difícil deixar de incursionar, num ou noutro ponto, em questão já ventilada.

O fato poluidor não é novo, nem é nova sua tratativa pelo ordenamento jurídico. A título de exemplo, no século passado, já se empregava o termo poluição dos despolpadores de café no Estado de São Paulo, constatando-se o lançamento de resíduos nos rios. Tanto na Europa como na América do Sul, desde há muito tempo, regulamentos foram editados para se tentar evitar o desmatamento indiscriminado.

No correr do trabalho examinaremos que não só leis e regulamentos inadequados contribuíram para o avanço dos ataques contra o meio ambiente, como a atuação de administrações que se revelaram ineficazes para os seus objetivos.

\section{Crítica dos sistemas existentes}

Não temos a vã pretensão de examinar todas ou mesmo a maioria das legislações de administração ambiental. Acreditamos que, examinando os diferentes tipos de situações, poderemos retratar as razões dos resultados da política ambiental.

\section{Desenvolvimento econômico a qualquer preço}

Inicialmente deve ser enfatizado que somente na década de 70-80 pôde-se constatar um tratamento mais efetivo do problema. Além disso, cumpre colocar em relevo que o enfoque realizado foi diferente, de acordo com o grau de desenvolvimento econômico do país interessado. O emprego de medidas desenvolvimentistas sempre, ou na maioria dos casos, marginalizou as considerações ecológicas.

\section{Causas políticas da ineficácia: organização} centralizada

Respeitando o posicionamento interno dos países de regime unitário ou centralizado, temos, contudo, que constatar que o enfeixamento das decisões, da atuação e da execução da política ambiental, na prática, não fomentou o êxito dessa política. 
A Itália só recentemente veio a colocar em prática os princípios de sua constituição, levando a efeito o regionalismo; a Espanha, pela sua constituição de 1978, voltou a descentralizar-se; a França, intenta, agora, regionalizar-se; o Brasil, pela sua Constituição Federal de 1967 e pela Emenda Constitucional de 1969, centralizou diversas áreas atinentes ao ambiente.

O desejo de uniformizar leva o Estado "menos a uma repressão franca e policial que a uma opressão insidiosa caracterizada por encarregar-se do conjunto dos comportamentos e mesmo pela integração das diferenças nas inștituições especializadas ditas 'sociais' que vão do hospital psiquiátrico ao local de educação fiscalizada."1

Como salienta Charles Debbasch, "em um sistema de centralização, não há vida administrativa fora dos órgãos centrais. São os únicos habilitados a tomar as decisões administrativas para toda a extensão do território. Essas decisões são imputadas ao Estado, única pessoa jurídica reconhecida. Sem dúvida, em um tal sistema nada impede as autoridades centrais de adaptar sua ação à cada parte do território, mas, de fato, distanciadas das preocupações locais, essas autoridades são tecnicamente ineptas, fora dos casos excepcionais, a realizar essa adaptação."2

O problema da centralização não se reflete somente no estado unitário. Certos países, onde o regime é federal, o centralismo das administrações provinciais ou regionais, tem deixado as populações locais sem resposta a seus apelos pela modificação ou melhoria de seus ambientes. A presença de funcionários nos locais dos fatos - mas sem poder de decisão - transforma-os em "simples caixas de correio" na expressão do administrativista francês mencionado, fazendo com que as populações se desestimulem a agir. Aliás, o centralismo das decisões é uma técnica organizadora destinada a favorecer os que facilmente podem chegar ou dirigir-se ao centro - as classes economicamente mais fortes - relegando aó esquecimento os reclamos dos que não podem locomover-se para pressionar ou mesmo para legitimamente solicitar. A verticalização das decisões tem prejudicado contínua e consideravelmente o meio ambiente, pois na distância e isolamento dos gabinetes, os componentes naturais da decisão ambiental não chegam sequer a ser inventariados.

Cumpre assinalar, também, que a descentralização administrátiva, geralmente, desconhece os limites dos ecossistemas sobre os quais opera. Assim, surgem decisões contraditórias num só ecossistema que mereceria igual ordenamento jurídicoadministrativo.

\section{Causas administrativas da ineficácia}

\section{Ausência de organismos com ação coordenadora}

Na Espanha, critica-se a ausência de eficácia coordenadora na Comissão Interministerial do Meio Ambiente - CIMA3; na Argentina, aponta-se a falta na administração nacional de um órgão interministerial coordenador da atividade da Secretaria de Estado de Recursos Naturais y Ambiente Humano - SERNAH com a de outros muitos organismos nacionais que têm responsabilidades ambientais ${ }^{4}$; no Brasil se'nota, também, a ausência de uma ação coordenadora da Secretaria Especial do Meio Ambiente - SEMA, em assuntos como a produção do álcool, pois a mesma se encontra ausente tanto do Conselho Nacional do Álcool - CNAL, como da Comissão Executiva Nacional do Álcool - Cenal5.

Não só no plano horizontal, isto é, nos organismos administrativos do mesmo nível de poder notase a ausência de coordenação. A falta de harmonização e de integração também é encontradiça nos países federais onde, ou se chocam políticas dos diversos planos ou se registra a inércia de uma das áreas - local, regional ou estatal - , com a hipertrofia da outra área.

Nem todos os governos têm uma política de conservação explícita: as políticas que existem são muito estreitas e setoriais. Portanto, o perigo reside em que se descuide das oportunidades para um planejamento e uma realização conjuntos dos requisitos de conservação da agricultura, da silvicultura, da pesca, da fauna silvestre e assim por diante 6 .

\section{Ausência de pessoal capacitado}

O fracasso de muitos planos ambientais tem sido devido à ausência de conhecimentos especializados por parte dos encarregados públicos e privados da conservação ambiental. Os problemas oriundos do crescimento das metrópoles, as mudanças de atividades nas zonas rurais, o emprego de novas tecnologias e a busca do produtivismo pegou de surpresa muitos países, que não investiram na estruturaçaõ de escolas para formação de especialistas em nível médio ou superior.

De outro lado, ressentem-se os novos formados nessa nova especialização - a ecologia - de um estatuto profissional, garantindo-lhes o acesso aos organismos administrativos e o exercício prioritário das atividades da área. Essa regulamentação profissional não visa excluir outros profissionais do setor, como biólogos, engenheiros-agrônomos, engenheiros-florestais, geógrafos, etc.

Para os profissionais já anteriormente capacitados tem feito falta a prática da atualização de conhecimentos. Necessitam os organismos adminis- 
trativos ambientais de regulamentarem a freqüência a novos cursos pelo pessoal administrativo - incluindo os pesquisadores. Dessa forma, haverá uma permanência da inquietação intelectual nesses diplomados e a obrigatoriedade de aumentarem e redimensionarem seus conhecimentos gerais e especializados.

A ausência de comprovação da capacitação inicial e subseqüente para integrar um organismo administrativo ambiental tem sido uma das causas de seu insucesso. Em muitos países domina o favoritismo nas escolhas do pessoal, o clientelismo eleitoral como parâmetro para a admissão, o companheirismo ou a filiação partidária, resultando no ingresso dos menos aptos. O marasmo, a lentidão e a inércia de muitos órgãos se devem a esse lamentável sistema de escolha dos profissionais.

Órgãos administrativos de ação descontínua e sem independência de ação

Temos que distingüir entre a micro e a macrodegradação da natureza. A primeira geralmente é praticada pelo indivíduo isoladamente. Ainda que seja nociva, no cômputo da deterioração não tem aguda conotação. Já a macrodegradação é feita pelas empresas nacionais ou transnacionais ou pelo Estado, atualmente, quando se dedica à exploração da atividade industrial. Assim, levando-se em conta que os outros grupos e segmentos sociais não se encontram organizados e atuantes, evidencia-se que a condução e a formação da vontade política do Estado não tem passado pelo necessário debate, mormente no que concerne aos problemas ambientais. Dessa forma, a política ambiental que vai orientar e dirigir a burocracia pública nem sempre opta pelas meIhores soluções a curto, médio ou longo prazo. Freqüentemente depara-se com a burocracia não tendo meios jurídicos de se opor às decisões de cunho político.

Aos segmentos poluidores tem interessado, portanto, desestabilizar o quadro burocrático especializado em meio ambiente. A insegurança na relação de emprego tem levado os administradores ambientais a agir com parcial ou nenhuma independência diante das pressões sofridas. Dessa forma, constata-se que, em alguns países, a descentralização por serviços criou empresas públicas ou agências, em que seus empregados têm, por delegação, o poder de polícia ambiental, mas não têm nem mandato ou contrato de trabalho a prazo fixo e nem estão enquadrados no sistema estatutário.

Métodos inadequados de ação administrativa de controle da poluição.

A ausência de experiência e de pesquisa de novas e apropriadas técnicas de controle da emissão de poluentes tem levado muitos países em desenvolvimento e subdesenvolvidos a copiar ou tentar copiar integralmente os objetivos de qualidade e as normas de emissão dos países desenvolvidos. O desconhecimento da própria reação dos ecossistemas locais dificulta e leva ao insucesso a ação administrativa pela importação tecnológica nem sempre adequada.

\section{Sistemas orçamentários impróprios}

O constitucionalismo moderno não conseguiu ainda armar uma estrutura em que na divisão das funções e dos serviços públicos, se deixe, a cada ano fiscal, de ter que negociar, pressionar ou simplesmente esperar pela atribuição de determinada receita. Disso decorre a instabilidade dos planejamentos e da ação em serviços de conservação notadamente de parques e de reservas biológicas. Assinale-se que a remuneração dos profissionais das administrações ambientais fica ao sabor dessas flutuações, sendo os bons valores atraídos pelo mercado privado de trabalho ou agem, esses profissionais, para privatizar a administraçao pública ambiental, em busca de melhores salários.

\section{Sistema proposto: fundamentos e princípios}

\section{Nova conceituação de meio ambiente como patrimônio público e a intensificação da participação popular na gestão e controle dos recursos naturais.}

As res communes omnium e os bens integrantes da propriedade pública coletiva, na concepção apropriada de Massimo Gianini, não integram simplesmente os bens públicos dominiais, como ilustres juristas afirmam. Como assinala o administrativista italiano, na propriedade coletiva "o bem deve ser idôneo a proporcionar, por sua natureza, um serviço indivisível (estradas, lagos, jardins) ou por obra de homem, ou por causa econômica, ou composta, um bem abundantemente in rerum natura, consistindo para o ordenamento jurídico não na propriedade mas na frúição dos serviços que a coisa proporciona ou é idônea a proporcionar se empregada convenientemente"

O Estado ou o poder público no caso de bens ambientais é mero gestor desses bens, tendo em vista seu uso coletivo. Avultam aqui a atividade e a organização administrativa pública na finalidade de velar pelo racional e adequado uso coletivo do bem. Atualmente se acentua com justeza a função social da propriedade privada, mas olvida-se de afirmar a função social da propriedade pública. E não seria truísmo fazê-lo, pois o que se vê é o poder público 
comportando-se habitualmente como um proprietário privado, pretendendo dispor e usar desses bens para fins outros que a fruição da coletividade.

$\mathrm{Na}$ Argentina, pode-se assinalar que "los recursos naturales se estan desplazando de la propriedad y dominio particular al dominio público". " Caso típico puede encontrarse en la ley de vialidad argentina, en la que con carácter general han sido expropriadas todas la canteras, a efectos de facilitar las obras viales." 8

No Brasil, a fauna silvestre deixou de ser res nullius para ser bem público, conforme a Lei N. 5.197 , de 3 de janeiro de 1967. Acentuamos que "a União não pretendeu submeter a fauna silvestre e seu habitat a um regime jurídico de direito privado, para que a fauna fosse vendida, permutada ou explorada economicamente."9 Assim, não se substituiu ao proprietário privado pelo Estado - empresário. O Código Ambiental Colombiano de 1974, artigo 42, declara os animais e peixes silvestres como pertencentes ao domínio público.

Como bem ressaltou o Progetto 80 "ao reconhecimento do caráter dos recursos naturais como bens coletivos devem corresponder novas leis e estrutura organizadora adequada à sua tutela e à sua fruição por parte da coletividade."10

Buscando evitar tergiversações no entendimento legal sobre o meio ambiente, foi inserido na Lei de Política Ambiental Brasileira de 1981 sua conceituação como "patrimônio público a ser necessariamente assegurado e protegido, tendo em vista o uso coletivo."

O posicionamento legal sobre a insofismável destinação dos bens ambientais há de levar a um novo sistema orgânico de administração ambiental, onde não só o poder público será representado, mas também as associações que defendam os valores sociais do ambiente. Uma nova estrutura organizadora merece ser concebida, como veremos.

\section{Novos métodos de ação administrativa ambiental: motivação dos atos e informação}

- "La administracion pública no es representante de la comunidad, sino una organizacion puesta a su servicio, lo cual es en esencia distinto. Sus actos no valen por eso como propios de la comunidad - lo que es lo característico de la ley, lo que presta a esta su superioridad y su irresistibilidad - sino como propios de una organizacion dependiente, necesitada de justificarse en cada caso en el servicio de la comunidad a la que está ordenada." 11

Essa oportuna afirmação dos juristas espanhóis precisou passar, inclusive, para os textos de leis para que a administração pública se visse obrigada a dar as razões de seus atos perante a coletividade. A divisão dos atos administrativos entre regrados e discricionários, levou muitos doutrinadores a entender que a discricionariedade não determinava a motivação desses atos. Partia-se do pressuposto de que todos os atos da administração, por si só, eram realizados no interesse público. Daí a instituição dos quadros burocráticos estatais distanciados da população, dela recebendo seus impostos e taxas, mas a ela não se sentindo obrigados a explicar as razões de seus atos. A administração passa a ficar acima do bem e do mal, numa ação "autodivinizadora".

Não só com referência aos direitos individuais, mas também aos direitos sociais e, notadamente, na gestão dos bens ambientais, a ausência de fundamentação dos atos da administração tem levado ao aumento da poluição e da devastação da natureza.

"Deve existir por parte do administrador uma disposição aceitável de meios e fins, de modo a alcançar-se o consenso e a cooperação mais concretos possíveis entre os interessados. Este esforço não é inofensivo, pois leva a uma considerável sobrecarga da racionalidade da decisão, obrigando à admissão de várias informações e objetivos secundários no decurso da decisão." 12

A motivação dos atos da administração ambiental vai obrigá-la a buscar as informações e não só admiti-las no processo decisório. Obrigando-se a motivar, evidentemente esses motivos devem existir e serem apontados, discutidos e sopesados. " $\mathrm{Ha}$ de dar razón plena del recurso lógico y jurídico que ha determinado la decision."13 Além disso, a autoridade administrativa tem a "obrigação de se situar nas melhores condições para fazer uma sã apreciação da oportunidade de sua decisão." 14

Legislações de vários países caminharam para exigir a motivação de determinados atos administrativos. A Espanha (1963), a República Federal da Alemanha (1976), Portugal (1977) e a França (1979) 15 passaram a exigir explicitamente que fossem apresentados os motivos de fato e de direito de determinados atos administrativos.

A Lei da Política Nacional do Meio Ambiente do Brasil afirma que os órgãos administrativos "deverão fornecer os resultados das análises efetuadas e sua fundamentação."

A procura dos motivos e não de quaisquer fundamentos, mas daqueles que sejam convincentes e adequados para a decisão, tem direcionado para a adoção dos estudos de impactos ambientais. São a antecipação e a prevenção dos males ecológicos, demonstrando que a administração procurou se assenhorar de todos os elementos para bem-decidir. 
A clareza, a seriedade, a logicidade dos motivos da decisão da administração ambiental (autorizando um complexo industrial, licenciando uma indústria, abrindo uma temporada de caça, localizando um parque ou uma reserva, autorizando a extração de árvores ou a modificação das essências florestais, o indeferimento ou a revisão dessas medidas) são pressupostos imprescindíveis para uma vida social com liberdade individual e solidariedade participativa.

- A presunção de legitimidade de que gozam os atos administrativos não é princípio jurídico destinado a esconder as intenções e o processo decisório da administração. Vivemos uma época de comunicação de massa. Informar, muitas vezes significa manipular os informados.

Os males ambientais têm-se agravado nos países que ocultam primeiramente a realidade do ambiente e em segundo lugar que conservam os administrados na ignorância de suas tratativas com os agressores da qualidade da vida.

A formação da opinião ecológica da coletividade passa evidentemente pela qualidade da informação que se lhe proporciona.

Não basta assegurar-se o direito à informação ambiental perante as administrações. Assim afirmamos, pois o direito à informação se baseia na ação do informado. Istoé, quem está sendo vítima ou pode ser vítima dos gravames ecológicos ou vê a natureza em perigo é que deve enfrentar as naturais dificuldades de agir (peticionar, ir à repartição pública, enfrentar despesas, etc.). Ora, no direito ambiental e em sua organização administrativa deve-se estabelecer, sem ambigüidades, uma dupla mão de direção: direito de informação e dever de informação.

Ficaria só no terreno das boas intenções um dever genérico de informar sobre o estado do meio ambiente. Em muitos países instaurou-se a prática de pelo menos um relatório anual sobre a qualidade do ambiente. As leis e os regulamentos deverão expressar o dever não só de coletar dados sobre o ambiente, como de publicá-los com periodicidade. Informação que deverá conter indicações claras para que a população, de todos os níveis de cultura e não só os especialistas - , se inteire e tenha elementos para possíveis interpelações da própria administração.

Propor a participação da população e sonegarIhe a informação é concretamente anular a presença dos cidadãos em toda a ação administrativa.

No Brasil tenta-se, também, levar ao conhecimento operativo da opinião pública as pretensões dos que venham a exercer atividades poluentes ou potencialmente poluentes. Antes que a administra- ção se posicione juridicamente, ainda há chance de se pedir explicação, de se negociar ou de conciliar as diferentes posições. A Lei da Política Nacional do Meio Ambiente dispôs que "os pedidos de licenciamento, sua renovação e a respectiva concessão serão publicados no jornal oficial do Estado, bem como em um periódico regional ou local de grande circulação." Contudo, a nível de prática, o conteúdo dessa publicação não ficou estabelecido e as legislações dos estados-membros e dos municípios não implantaram, ainda, essa sistemática.

\section{Consulta prévia da população sobre projetos que possam deteriorar o ambiente.}

Os assuntos ambientais deram oportunidade para uma marcante inovação, em quase todas as partes do mundo; os vários setores da população saíram da indiferença para as questões atinentes ao presente e ao futuro de sua quadra, bairro, cidade, região, país. O interesse não se fecha mais na fronteira política, diante, notadamente, da ameaça nuclear, das chuvas ácidas, da extinção das espécies. O mundo passou a ser visto como uma casa amplificada, recordando-se o grego primitivo do tempo de Homero, onde o habitat, o ambiente, era denominado oikos, para, depois, vocalizar-se como ecos, segundo Samuel Benchimol'16.

Do conhecimento dos fatos somado ao interesse surgido pela matéria ambiental, os cidadãos passaram a querer participar do procedimento de elaboração das decisões, já na fase de seu planejamento.

A França, desde 1917, levou à prática um procedimento de consultação prévia chamada enquete publique. Tal sistema prevê a presença no local interessado de um comissário designado pela administração que recolhe as observações escritas das pessoas que o procuram. Não há, todavia, um encontro formal e obrigatório dos cidadãos com os administradores públicos.

Nos Estados Unidos pratica-se o sistema de open meetings e de public hearings, mostrando uma administração áberta onde o público pode participar, assistindo a reuniões da administração pública e tendo oportunidade de apresentar, oralmente ou por escrito, seu ponto de vista.

Além do conhecimento em maior extensão das pretensões da administração pública, a população pode opinar. Contudo, não é uma votação dos cidadãos residentes no local. Dessa forma, a população a ser atingida pelas conseqüências da decisão não manifesta uma formal e vinculante posição sobre a atitude da administração. É um fato a ser sublinhado, pois essa consultação pública tem gerado 
grandes decepções, quando se vê a administração pública decidindo manifestamente contra as opiniões dos administrados consultados.

A consultação pública, entretanto, tem vantagem principalmente quando no sistema norteamericano (Administrative Procedue Act - §553. c) determina que, havendo relevância das considerações apresentadas, sejam elas incorporadas na decisão. Acreditamos que haverá interesse na cognição desses pontos de vista, caso haja recurso para o Poder Judiciário, que poderá apreciar a motivação apresentada pela administração pública. A contrasteação dos motivos servirá para a constatação do desvio da finalidade da decisão ou o excesso de poder utilizado.

\section{Administração participada: considerações gerais}

Em tempo não distante, foi preciso muito esforço para que o Poder Público deixasse de ser um mero observador dos fenômenos sociais e interviesse em várias funções da sociedade. Hoje, trata-se de estabelecer outra mão de direção, não para diminuir a anterior, mas, para, através da dupla direção, interagir em favor do interesse da coletividade.

A participação não pode ser vista como uma tolerância, um consentimento ou um favor da administração pública. Também, não se preconiza a privatização da administração pública. A presença dos cidadãos dentro dos organismos administrativos não é um intrometimento ou invasão em matéria que não Ihes diga respeito. Exige esforço, não há dúvida, eliminar-se a visão preconceituosa de que só os administradores públicos sabem e decidem bem e que a população "leiga" não tem capacidade para cogerir seus próprios interesses.

Participar é uma carga, às vezes, pesada. $\mathrm{Na}$ expressão de Michel Crozier é "perder a situação favorável de crítico confortavelmente instalado, é arriscar-se a se engajar emocionalmente, é, enfim, sujeitar-se a outrem ou ao grupo." 17 Não é de ser esperado um crescimento rápido da participação dos administrados, pois muitos temerão incorporar-se ao processo decisório com pruridos puritanos ou com receio de se comprometer no insucesso da administração.

A participação requer o exercício da liberdade de crítica desde a infância. Difícil pensar em participação efetiva em regime autoritário. E o espírito de crítica só se adquire com um mínimo de reflexão, que não é monopólio dos intelectuais. O hábito de lazer não-participativo, contudo, tem levado a população a ficar numa posição de expectadora inativa. No cotidiano, portanto, somos levados a nos demitir das responsabilidades sociais e comodamente, diante dos problemas que são nossos e de todos, jogamos a culpa nos governos, nos partidos políticos, nos eleitos, isto é, nos outros, sem deles solicitarmos ou exigirmos providências.

Compreensível que quem tenha necessidades individuais não-preenchidas (horas extras a fazer, distância da casa ao trabalho, má qualidade de habitação, ambiente profissional contaminado e agressivo, exploração salarial, cansaço diário acumulado...) não encontre ânimo para se agrupar na defesa de interesses que são seus também, mas cujas soluções nem sempre o atingem de forma direta e imediata. Assim, muitas vezes, estamos perante um fato cruel: a participação não se dá pela ausência de condições mínimas de vida e, contudo, essas condições não mudam, por falta de participação. Surge, então, a participação fragmentada em episódios (passeatas, greves e outras formas de protesto) em que se podem ou não colher frutos imediatos, mas as soluções tardam a chegar pela ausência de estruturação permanente.

Olhando para o passado vemos que a participação constitucional dos cidadãos na administração brasileira se reduzia ao direito de petição, de denúncia de abusos e de promoção da responsabilidade dos culpados (Constituição de 1891, artigo 72, §9.'). As outras constituições repetiram a idéia até o presente e as leis ordinárias não alargaram essa vereda participativa. Nem se pretenda que para essa ampliação se precisasse de previsão constitucional. No texto maior está regrado o mínimo no campo dos direitos individuais e sociais, não se limitando, porém, o acréscimo, por lei ordinária, desses direitos.

Os direitos de solicitar, denunciar e responsabilizar deixaram, contudo, o cidadão e o grupo social fora da administração. Não se possibilitou a efetiva fiscalização cívica da administração, nem sua cogestão, pela ausência de instrumentos legais. Ainda que não seja o nosso tema, saliente-se que a ação popular não tem sido amplamente utilizada, pois precisa ser reformulada.

Cogitamos aqui da participação dos cidadãos não uti singulus defendendo interesses estritamente privados ou próprios, mas uti cives ou uti socius como afetados pelo interesse geral, no dizer de Garcia de Enterria e Fernandez ${ }^{18}$.

A participação dos cidadãos e das associações não merece ser feita somente por via parlamentar. Como acentuam Steiger e outros, "não se pode esquecer que o sistema de governo parlamentar representativo nasceu no início do período da industrialização, quando as decisões a tomar não tinham conseqüências tão importantes para o indivíduo, como atualmente, quando os elementos e os processos de decisão não eram tão complexos como hoje e que, 
em decorrência, a organização das estruturas de decisão eram também mais simples." "Os procedimentos podem ser mais demorados, mas se trata de bens jurídicos primordiais como a vida e a saúde, que precisam ser vistos com prudência. Além disso, uma participação permitida no início, economiza, por conseqüência, procedimentos judiciais ainda mais longos."

Vale indagar acerca dos requisitos para uma sociedade civil vir a ser convidada para integrar um órgão administrativo. Diversas circunstâncias devem ser levadas em conta, além dos fins associativos: tempo de existência, número de sócios, inserção espacial, condições para ser associado, possibilidade de ação independente frente o Poder Público, etc. A escolha das associações ficaria ao alvedrio do administrador público ou seria útil a lei prever a presença de, pelo menos, algumas associações? É matéria cujo debate merece ser aprofundado.

Vão surgir, inevitavelmente, associações que só aparentemente postularão pelos interesses coletivos, quando, na realidade, foram criados ou para darem espaço a ambições pessoais ou para serem "testa-de-ferro" de interesses anti-sociais. Por simples temor do associativismo cívico não se pode condená-lo, ignorá-lo ou marginalizá-lo.

A perda da liberdade de opinar e de agir das associações pode ser encontrada no seu atrelamento ao poder público, pelo caminho de subvenções, contratos ou outro tipo de ajuda. Não se deve vedar a possibilidade de que o dinheiro público financie os grupos que se destinem a proteger o próprio interesse coletivo. $\mathrm{O}$ que se deve ensejar é a oportunidade das associações (que preencham certos requisitos previstos em lei) terem direito a receber ajuda. Evita-se, portanto, a subserviência participativa.

A rotatividade das associações nos organismos administrativos alargará o campo de participação e trará novas energias e, quem sabe, pontos de vistas diversos.

Tem sido apontada a politização das associações como um mal-estigmatizador. Quem assim afirma, parte de um preconceito de que a militância partidária conspurca ou serve a interesses somente pessoais. Confunde-se eleitoralismo, isto é, ação visando captar votos, sem cumprimento dos compromissos pré-eleitorais, com partidarismo consciente e ativo. As associações não devem pretender ocupar o lugar dos partidos políticos como também não podem ser por estes manipuladas, devendo respeitarse mutuamente cada uma das entidades em causa, como acentua Bernard Haering ${ }^{19}$. Os contatos, o entrosamento de idéias e de atividades, cada um conservando a sua identidade, será altamente vantajoso para o interesse das associações e dos parti- dos políticos, que nada mais é do que o bemcomum.

A existência das associações não depende de aprovação nem expressa nem implícita da administração pública. O Código Civil Brasileiro classifica essas sociedades como pessoas jurídicas de direito privado (artigo 16, §I) tendo a mesma existência legal, a partir da inscrição de seus estatutos ou atos constitutivos no Cartório de Registros Públicos (artigo 120 da Lei n. 6.015, de 31 de dezembro de 1973). O procedimento de registro passa incialmente pelo exame do oficial do cartório de Registros Públicos, que analisará o ato constitutivo sob os aspectos da legalidade dos fins ou das atividades pretendidas, se visam ou contrariam o bem-público, a segurança do Estado e da coletividade, a ordem pública ou social, a moral e os bons costumes, conforme o artigo 115 da mencionada lei. Encontrado os motivos negativos apontados, o oficial do registro suspenderá o processo de registro, iniciando o procedimento de dúvida perante o juiz corregedor competente. Caso concreto pode ser apontado na Comarca de Cubatão-SP, onde o oficial do Cartório suscitou a dúvida e, com parecer bem-fundamentado do Ministério Público, o juiz de Direito acertadamente repeliu a dúvida e determinou a inscrição da Associação Contra a Poiuição e as Más Condições de Vida de Cubatão.

$\mathrm{Na}$ França, recentemente, instituiu-se o sistema de associações autorizadas e não-autorizadas. Não se eliminou a participação das associações livres, mas se privilegiou a intervenção das autorizadas. Michel Prieur aponta que "as associações nãoautorizadas dispõem de numerosas ocasiões para participar dos organismos públicos. Um estado de espírito novo vai reforçar esta associação dos interessados na tomada de decisão concernente à sua vida em geral. Deseja-se que a autorização não seja um filtro cômodo para eliminar os que incomodam."20

Como se pode exigir preparação cultural para o desempenho da função pública, também, a participação pode ser orientada no sentido de se buscar a cooperação de entidades especializadas. Na prática administrativa da República Federal da Alemanha se constata o hábito de se procurar parecer técnico de toda a modalidade profissional. Massimo S. Gianini põe em relevo que, na Itália, o progresso tecnológico desempenhou o papel de multiplicador de serviços e de prestações distribuídas pelas administrações públicas. Sublinhe-se, contudo, que sob o pretexto de especialização das tarefas não se faz válida a antiparticipação. Bernard Haering insiste que muitas vezes os tecnocratas e cientistas assumem "atitudes de homens elitários e arrogam-se o direito de decidirem pelas massas". Suas decisões são 
as mais nocivas formas de manipulação permitindose "invadir os campos da liberdade e da dignidade humana".

A intervenção de entidades especializadas procurando resguardar os interesses comunitários tais como o Ministério Público ou o Ombudsman, notadamente nos Países Escandinavos - , não ocupa totalmente o espaço onde as associações podem e devem movimentar-se na administração pública.

A administação participada merece ser colocada em marcha não só para conservação dos valores e dos recursos naturais e na defesa do consumidor. Massimo S. Gianini assinala outros setores em que a prática italiana faz a consulta aos portadores de interesses coletivos: planos territoriais, planos setoriais de atividade econômica, determinação de preços e tarifas, determinação de cláusulas de importação e exportação, determinação de cláusula geral de produção de bens e de serviço, determinação para a aplicação das normas disciplinadoras dos poderes de empreiteiros, aplicação de normas tributárias, ainda que imponham prestações instrumentais ${ }^{21 .}$

Como bem ressalta o austríaco $\mathrm{R}$. Walter, citado por Garcia de Enterria e Fernandez, os fenômenos de participação dos cidadãos no funcionamento da administração têm sua justificação específica, não como busca de decisões "justas" frente a decisões "injustas" no plano dos valores jurídicos finais, que é próprio da lei, mas no âmbito da discricionariedade, onde o que interessa é precisar o oportuno "diante do 'inoportuno"'." "A oportunidade da decisão se mede não por uma simples perfeição técnica em sua preparação e concepção, senão por sua adequação às solicitações sociais e por sua aceitação no corpo social, previamente investigada, além de promovida por técnicas participativas."

Os integrantes - estatutários, contratados comissionados ou nomeados - da administração pública não esgotam em si mesmos a representatividade do interessse coletivo. É falso, portanto, situarse o Estado defendendo, com exclusividade, o interesse coletivo, colocando-se um fosso de separação entre as associações e os indivíduos de um lado e do outro o poder público.

Espera-se que a implementação de reformas jurídicas venha realmente abrir a participação do cidadão associado nos organismos federais, estaduais e municipais, acautelando-se que a reforma pretendida não visa transmudar o que é público para feudo de grupos minoritários ou em panacéia de insucessos administrativos premeditados.

Acentue-se também que a participação das associações não pode ser pretexto para legitimar governos que não pratiquem o sistema representativo em sua inteireza, como acentua o professor Charbonneau, da Universidade de Bordeaux ${ }^{22}$, que alerta, além disso, para que as associações não se prestem a fazer passar decisões que a administração, por si só, não seria capaz de conseguir a aprovação.

A participação da população em geral na ação administrativa ambiental tem sido uma das características da legislação e da política norte-americana expressa, por exemplo, na Section 101-e do Federal Water Policy Control Act, que afirma "a participação do público no desenvolvimento, revisão e cumprimento dos regulamentos, padrões, limitação de efluentes, planos ou programas estabelecidos pelo administrador ou por um Estado na aplicação desta lei deve ser prevista, encorajada e assistida pelo referido administrador ou pelos Estados. $\mathrm{O}$ administrador em cooperação com os Estados, deverá desenvolver e publicar regulamentos especificando o mínimo de regras para a participação do público em tais processos."

\section{O colegiado: uma forma de administração ambiental participada.}

O colegiado exprime a possibilidade de se fazerem presentes diversos entes públicos e privados, ou somente públicos. É uma fórmula de organização que pode possibilitar a coordenação de setores dispersos. Sublinhe-se que a coordenação de que se fala não representa hierarquização de posições, mas ajustamento de políticas desde o planejamento, discussão, decisão e acompanhamento da implementação do ato deliberado.

Na administração pública ambiental está-se preconizando a sua adoção como uma oportunidade de maior participação de todas as áreas públicas e privadas interessadas. Ressalte-se que, conforme forem as pessoas e entidades componentes do colégio, desde o início, se dá ao mesmo possibilidade ou não de agir pela melhoria da qualidade de vida, pois é importante saber como se atingirá o quorum de votação e qual o número de organizações representadas.

Muitas vezes representará uma mistificação a presença de associações ambientalistas em um colégio, em que o posicionamento desses grupos será intencionalmente minoritário e, no entanto, darão quorum para a reunião do colégio e para a aprovação de medidas antiecológicas.

A qualidade intelectual e moral dos membros do colegiado merece ser sempre pesquisada para que se evite a presença de personnalités de complaisance ${ }^{23}$ na expressão de Jean Lamarque ou até a cialtroni apontada por Massimo Gianini24.

"Um colegiado para poder funcionar bem, de- 
pende primeiramente da clareza com que suas finalidades são definidas e, portanto, do dimensionamento de sua competência. Se for deliberativo ou se for somente consultivo variará a força dos pronunciamentos do órgão.

O critério de escolha dos componentes do colegiado, os requisitos prévios dessa opção e composição, a duração do mandato, o processamento das votações, a freqüência às reuniões e o modo de convocá-las, entre outros dados, mostram a possibilidade de eficiência de um órgão coletivo.

Importa saber se as deliberações do colegiado são públicas no decorrer da sessão ou - se após a deliberação ou a manifestação consultiva - os votos serão tornados públicos. Disso dependerá a possibilidade dos administrados se inteirarem da maneira como as decisões foram tomadas e terem oportunidade de elogiar ou criticar o posicionamento dos que devem zelar pelos seus interesses.

A periodicidade ou regularidade das reuniões será ou não sinal de eficiência do organismo, pois a rápida fluência das matérias apresentadas evitará a confirmação do pensamento popular de que quando se quer resolver um assunto atribui-se a matéria para a responsabilidade de uma só pessoa, e quando se pretende procrastinar, confere-se a responsabilidade da solução a um colegiado.

É preciso evitar-se alguns obstáculos como: as questões a serem debatidas já vêm com soluções imutáveis, tornando inócuo o debate; a ausência de obrigação de freqüência dos componentes dos órgãos, causando posterior reação de insurgência contra as decisões tomadas, ainda que a reação seja de forma sub-reptícia; diluição da responsabilidade pessoal do membro do colegiado ante a decisão coletiva (defeito que se remove tornando obrigatório o pronunciamento de cada um dos membros e a motivaçao de seu votol; ordens do dia preparadas de forma superficial e apressada, sem que se enviem as matérias com å necessária antecedência, aos componentes do órgão." 25

Em seu estudo sobre metropolização e meio ambiente, Jorge Wilheim sugere que "para aumentar a relação entre a sociedade civil e a administração da mesma, todo o órgão que preste serviços seja orientado por conselhos mistos compostos por: cidadãos representantes da população da região; cidadãos representantes dos interesses de classes da região; representantes do governo. Este sistema de co-gestão deveria certamente fazer com que a ação governamental se dedicasse à prestação de seviços, com as prioridades de maior demanda, evitando assim os excessos tecnocráticos." 26

\section{Sistema orgânico de administração ambiental}

\section{O conceito de sistema e a administração}

"Se no mundo ambiental se mostra uma tendência para o esgotamento dos recursos econômicos naturais ou para a destruição ou deterioração ecológica, passou o Estado a ser coagido a realizar políticas destinadas a neutralizar tais tendências. Por outra parte, dado que o mundo ambiental constitui por si um sistema complexo, chamado freqüentemente ecossistema, composto de distintos componentes ou subsistemas interagindo entre si, uma ação sobre o setor ambiental S pode ter efeitos positivos ou negativos sobre os setores $S^{\prime}$ e $S^{\prime \prime}$, daí se concluindo que a complexidade ambiental sofre o da complexidade das políticas estatais seguidas." 27

A administração pública que pretenda intervir e agir sobre o meio ambiente, defendendo-o e transformando-o, não pode marginalizar o sistema ecológico. "Um sistema ou complexidade organizada que pode ser definida pela existência de fortes interações não lineares." 28

\section{Repartição de competências e administração ambiental}

Dependendo da extensão de um país, temos somente a realidade política estado e município. Comumente, contudo, o que se depara modernamente é a existência do estado, da região e do município. A quantidade de poder ou de atribuições divididas entre esses entes vai depender do regime constitucional do país. Culturalmente, contudo, dificilmente se pode desconhecer a existência da região e do município, ainda que se Ihes negue personalidade de direito público.

A utilização do termo descentralização tem sofrido críticas, pois "dá margem ao erro de ser entendido como desprendimento, renúncia, abandono por parte do estado de atribuições próprias, quando o que se descentraliza, por justiça e com reta oportunidade, não é mais do que a autarquia, a autonomia inerentes à perśonalidade e que tutelarmente se retiveram, se porventura não usurparam, à independência natural e à atual capacidade das demais pessoas que não o estado" como acentua Gil Robles, citado pelo professor José Pedro Galvão de Souza. Este publicista acentua que "a descentralização política implica no reconhecimento da capacidade e direitos de entidades autônomas em face do poder do estado."29

Administrar o meio ambiente, formular uma política ambiental evidentemente passa pelo problema da distribuição de competências. É preciso 
esmiuçar-se um pouco mais, para se saber quais as questões que poderiam interessar ao estado, à região e à localidade. Algumas constituições mencionam na divisão das atribuições não o meio ambiente, mas alguns de seus componentes, como defesa e promoção da saúde, as águas, as florestas, caça, pesca, jazidas, energia hidrelétrica, energia nuclear, etc. No estabelecimento da competência sobre essas matérias geralmente se tripartem as atribuições em exclusiva, concorrente e suplementar. Assim, a divisão se dá ratione materiae e ratione loci.

Desde já, sublinhe-se a diferença dos subsistemas abrangidos, como também, a diferença entre as próprias regiões e municípios de um mesmo estado. Válida a crítica de Oliveira Viana de que se persiste "neste preconceito de igualdade a todo tran$\mathrm{se}^{\prime \prime}$, tratando-se as diversas unidades regionais e administativas (municípios ou estados) sob um mesmo padrão teórico - como se todas elas tivessem a mesma cultura política ou a mesma estrutura social." 30

A fixação das normas de emissões, ou seja, o estabelecimento da qualidade e quantidade de resíduos que possam ser lançados nas águas, no are no solo é matéria que exige alta indagação científica, realização de testes, averiguação da saturação dos meios receptores, entre outros dados. Essa tarefa exige um adequado investimento de recursos financeiros e pessoal habilitado. A maioria dos municípios e quem sabe algumas regiões de muitos países não estariam capacitadas para cumprir tal trabaIho. Contudo, as exceções podem ser encontradas. Seria adequado uniformizar e tornar exclusiva essa atribuição e dela encarregar-se um dos entes políticos? Cremos que não. E pelo fato do estado ou da região estabelecerem o índice permitido de poluição, o município deveria ser impedido de ser mais benevolente ou ser mais rigoroso, ampliando ou restringindo? Se a legislação local fosse mais benevolente, não se atrairia a poluição para a'localidade?

A nosso ver surge, então, e desde agora, a oportunidade de se afirmar que o meio ambiente merece ter da parte dos países primeiramente uma política global, ampla e geral. Não se pretende uma política uniforme, mas que examine as desigualdades ecológicas, econômicas, demográficas e culturais e Ihes dê o tratamento devido. É uma atribuição natural do órgão administrativo que puder ter essa visão de conjunto. Não uma visão compartimentada, que segmente as partes analisadas, mas que leve em conta as interações dos diversos fatores.

Antes de prosseguirmos, traga-se uma realidade ambiental: os corpos hídricos. Como pensar em tratar a água de uma forma restrita a uma região ou a um município, sem levar em conta a calha central e os afluentes de uma bacia fluvial? Como isolar só a água da superfície, esquecendo da subterrânea? Citando uma das faces do problema da poluição das águas, de nada valeria tratarem-se dos dejetos lançados a jusante, se a montante próximo os resíduos não forem tratados. Se se desviarem as águas de uma bacia ou se se construírem represas, evidentemente o ambiente será mudado não só no local, mas em outros pontos da própria bacia.

Tratar os resíduos sólidos muitas vezes é tarefa difícil para o município que faz a coleta desses resíduos. O consórcio entre municípios para reciclagem do material ou para sua compostagem tem sido utilizado.

De outro lado, a ocupação do solo, a localização das indústrias, o controle da poluição atmosférica fala bem de perto aos moradores da localidade ou para aqueles que estejam na vizinhança do foco emissor do poluente.

Assim, sem nenhuma dificuldade, se constata que não é eficaz para a resolução dos problemas ambientais igualar as atribuições do poder central e dos outros centros de poder autônomo. A autonomia para administrar as questões ambientais, portanto, não deve ser mensurada da mesma forma.

Se os problemas da fixação de normas de emissão e de padrões de qualidade, de zoneamento ecológico-econômico e de licenciamento não podem ser atribuídos da mesma forma a regiões diferentes ou municípios dessemelhantes, nem por isso se deve impedir que as entidades menores possam também ter competência no controle ambiental.

Ineficaz é concentrar todo o controle no órgão central ou na administração regional, amputando-se a manifestação dos que mais perto estão de alguns problemas. É sabido que na comunidade local, como salienta Ernst Forthoff há "o controle mais intenso dos eleitores e da opinião pública sobre relações mais simples que se refiram a setores mais restritos". "A vizinhança existe naturalmente ná relação cidadão e comuna, a distância na relação com o Estado". Acrescenta que "se a distância aumenta cresce ainda a possibilidade de uniformidade e da subordinação à experiência e ao conhecimento técnico." 31

Levando-se, pois, em conta as peculiaridades apontadas, importa organizar um sistema em que as administrações públicas central, regional e local se reúnam, regularmente, de modo institucionalizado, para que não só nos casos de calamidade, mas, rotineiramente, possam interagir. Não se trata de hierarquizar contatos, mas uma fórmula de conciliar atividades e manter abertos os canais de participação e comunicação dos municípios com as regiões, dos 
municípios com o estado e deste com os entes autônomos mencionados. A concepção de um sistema nacional de meio ambiente poderá possibilitar essa participação integrada, inobstante venham a mudar as regras constitucionais que dimensionem a autonomia das regiões e das municipalidades.

\section{Unificação ou redundância de serviços pú- blicos ambientais}

Freqüentemente se diz que é preciso evitar-se a duplicação de serviços. Critica-se nessa duplicação o aumento das despesas pública e a ausência de uma mesma direção ou cọmando administrativo. Alfred Sauvy chega a afirmar quando trata da necessidade de dividir os "grandes corpos administrativos" que "todo neófito da ciência administrativa não deixa de ficar chocado par les doubles emplois não deixando, também, de preconizar concentrações e coordenações." 32

A redundância dos serviços, contudo, não tem trazido por si só a ineficácia do serviço público. Não se pode esquecer a eficácia como princípio de legitimidade da administração ambiental, definindo-se a mesma como a "capacidade efetiva de satisfazer as crescentes demandas que apresenta a sociedade", consoante afirma Garcia-Pelayo ${ }^{33}$.

"A redundância é geralmente definida como 'superposição inútil' ou o que os reformadores da administração americana chamam de 'duplicação'. Para os novos tecnologistas, contudo, redundância é um meio de proporcionar mecanismos de funcionamento seguro para manter o sistema operando, na suposição de que erros ocorrerão e de que a contínua operação de uma máquina ou uma organização requer outros canais por onde passem as comunicações e vários fatores que possam agir sobre os mesmos assuntos, quer juntos ou separados." 34

Parece-nos que nas questões ambientais não se podem criar oportunidades para uma administração monolítica fechada em si mesma, com unidade de canais de comunicações e de decisões, dandose, portanto, chance para erros de inoperância ou de ações malconcebidas ou mal-executadas. No Brasil existe a possibilidade da proteção do patrimônio natural poder ser realizada por órgãos federais separados (Secretaria da Cultura, através do Conselho Consultivo; o Instituto Brasileiro de Desenvolvimento Florestal - IBDF, através da divisão de parques, e a SEMA, através da criação de estações ecológicas e áreas de proteção ambiental), como também pelos estados-membros e pelos municípios. Na Suécia35, dividem-se as atribuições entre dois órgãos autônomos, a Comissão Nacional de Isenções para a Proteção do Meio Ambiente e a Comissão Nacional para a Proteção do Meio Ambiente (a primeira, compe- tente para licenciar as atividades que possam ter relação com o ambiente, assim como cancelar a licença e, neste caso, a pedido da segunda. Esta é competente para estabelecer os dados científicos da matéria ambiental e para fiscalizar as atividades que possam poluir ou que poluam efetivamente).

Na administração ambiental podem coexistir com eficácia, organizações que sejam semelhantes, mas cujas atividades não são necessariamente justaposições uma das outras, nem representem uma acavalamento ou interferência indébita. As interações serão registradas e se existirem conflitos de atuação, que venham tornar ineficazes os objetivos da política ambiental, seja a nível do estado, da região ou do município, então caberá ao órgão político, na sua mais alta acepção, arbitrar a divergência e decidir uma política coerente e eficaz. Essa arbitragem não será constante, mas só no momento do manifesto desencontro não-superado pela coordenação de um órgão superior.

\section{Um novo tipo de órgão administrativo ambiental?}

É de se perguntar da necessidade de um novo órgão ou de novos órgãos, expressamente no plural, destinados a tratar dos problemas ambientais. Não seria simplesmente aumentar a complexidade do quadro burocrático existente? O sistema social não se regularia por si mesmo?

Responde-nos, com acuidade, Michel Crozier: "a superioridade das democracias é tradicionalmente atribuída à sua maior abertura: um sistema é mais rico e mais eficaz por ser mais rico do que um sistema fechado, que se empobrece pela rarefação das trocas em seu interior e com o exterior. Isto é certo, com a condição de que não se esqueça, freqüentemente, que o sistema possa manter o mínimo indispensável de regulação. Do contrário, ele estará ameaçado pela entropia, isto é, pela degradação, lei geral de todo o sistema. É necessário um esforço constante de criação institucional para fornecer as regulações necessárias à sua manutençaõ e ao seu desenvolvimento." 36

Tendo-se em conta a natureza da atividade administrativa ligada ao meio ambiente, podem-se destacar, pelo menos, dois campos de atuação: o campo de decisão e controle e o campo da gestão dos recursos.

Na decisão e no controle mesclam-se as funções políticas e administrativas. Massimo Gianini anota a existência de atividades do Estado que não comportam direção política, mas só decisão administrativa ou no máximo uma direção política, mas só decisão administrativa, ou no máximo uma dire- 
ção política, sem regularidade ou em momento particular. São as atividades de gestão de pessoal, dos bens públicos, dos serviços públicos, dos recursos naturais, da ordem pública, da polícia sanitária, etc., atividades que comportam decisão de endereço político no momento de sua instituição, reforma ou supressão."37 "A separação institucional entre o controle político e as funções de regulação que ele enseja de um lado, e as responsabilidades operacionais de outro lado - sejam elas de gestão propriamente dita, de magistratura ou de animação - tal é, parece-me uma das mais importantes reformas a serem realizadas", assinala Michel Crozier ${ }^{38}$.

As instâncias políticas do estado, da região e do município, contudo, terão oportunidades ou de querer ou exigir a demonstração da prática das políticas concebidas, ou pretender a mudança do curso dessas políticas.

Os quadros burocráticos têm sido incriminados como lentos e de resultados inexpressivos e até imperceptíveis. Alega-se que o funcionário público, diferentemente do empregado privado, não correndo o risco da despedida ou do término da relação de emprego, fica improdutivo. A crítica é justificada e merece reflexão.

De outro lado, os funcionários sentem-se pressionados ou envolvidos por grandes organizações de interesses, através dos políticos ou diretamente. Garcia-Pelayo assinala que a "tecnoburocracia se entende melhor com os representantes das grandes organizações" 39 , registrando Bresser Pereira que "existe, inclusive, uma circulação de altos tecnocratas entre o setor público e privado, que facilita o entendimento." 40

Sem querermos trazèr novidades, insistimos, contudo, na procura de um novo tipo de organização administrativa que faça primeiramente com que seus integrantes sejam verdadeiramente motivados pela idéia a perseguir, isto é, amem e vivam as necessidades de defesa do ambiente desde o porteiro, passando pelas datilógrafas até quem decide e quem gestiona a natureza. Para isso, é preciso uma administração que tenha característica própria, portanto autônoma das demais. Por certo não será eficaz se for mais um bureau, impessoalizado como tantos outros, em que seus integrantes tanto poderiam lá estar como em qualquer outro.

Quando analisamos as deficiências das administrações atuais, colocamos em relevo a necessidade de se dar segurança aos seus funcionários. A solução razoável é procurar a soma de segurança com avaliação de rendimento do trabalho efetuado. Acompanhamos o pensamento de Michel Crozier que divide as funções desempenhadas pela burocracia em magistratura, gestão e animação. " Nas fun- ções mais tradicionais, aquelas que poderíamos chamar de magistratura no sentido mais amplo possível, são dominantes a aplicação e a interpretação de normas jurídicas ou regulamentos impessoais. São funções mais numerosas do que se acredita. Ultrapassam a função de justiça do estado. Acentua que muitos empregos possuem, em grau mais ou menos intenso, essas características: funções de controle e inspeção das legislações como o trabalho, a saúde, o meio ambiente." 41

Resguardando-se, pois, os serviços de controle de inspeção, para eles postulamos um regime jurídico de direito estatutário, ainda que se exija desses funcionários a freqüência de cursos e que se submetam a exames de avaliação periódicos. É de se denunciar que, sob pretexto de dinamizar a administração, tem-se transformado as carreiras, cargos e funções em empregos com contrato por prazo inteterminado, para que esses servidores públicos possam ser manipulados ou pressionados com maior amplitude. Contudo, com relação a servidores públicos incumbidos somente da gestão dos recursos naturais assim como aqueles incumbidos de trabalhos de pesquisa é de se admitir o sistema de contratos de duração limitada. Dessa forma, estes últimos seriam cobrados ao final do contrato e mais bemavaliados em termos de rendimento para a comunidade.

Queremos exemplificar na legislação do Quebec (1. de novembro de 1980) a adoção do sistema de mandato, isto é, prazo determinado e fixo para a investidura nas funções administrativas ambientais. O Escritório de Audiências Públicas sobre o Meio Ambiente é composto de cinco membros com mandato de no máximo cinco anos, que pode ser renovado e o Conselho Consultivo do Meio Ambiente, com uma certa diferença, com mandato fixo e de cinco anos para o presidente e de dois anos para os outros dez membros, sendo que o mandato dos membros não pode ser renovado consecutivamente senão uma vez.

Como acentuou Paulo Roberto Motta a "inovação em administração pública não constitui unicamente um problema de mudança dos padrões de racionalidade administrativa envolvendo reformas de estruturas, processo ou comportamento gerencial. Trata-se essencialmente de estabelecer condições organizacionais mais adequadas ao atendimento das demandas ambientais sobre a organização." 42

\section{O Ministério Público e a defesa adminis- trativa do meio ambiente}

O Ministério Público tem evoluído nestes últimos anos, firmando sua posição como defensor da sociedade. Em alguns países ainda conserva a tare- 
fa de defender também o Estado, mas não como função exclusiva.

Essa função vai-se colocar em relevo modernamente na defesa dos interesses difusos da coletividade, que tocam de perto o meio ambiente e o consumo, enfim, a qualidade da vida.

Em muitos países, o Ministério Público, conservando o princípio de autonomia funcional, não age por delegação do procurador-geral, mas atua segundo sua consciência. O que se denomina de "promotor natural", atuando pro populo e não pro domo sua.

Leve-se em conta que, em alguns países, o Ministério Público é independente do Poder Executivo, não the incumbindo a defesa dos atos da administração nem obedecer às ordens do ministro da Justiça. Veja-se como exemplo a Constituição do Estado de São Paulo em que o procurador-geral da Justiça é escolhido pelo governador em lista tríplice oriunda do Colégio de Procuradores de Justiça, com mandato de dois anos, podendo somente ser destituído pelo Colégio de Procuradores de Justiça em caso de abuso de poder.

Interessante notar um dos avanços do Ministério Público no Brasil, onde essa instituição passou a ter legitimidade processual para intentar a ação civil pública de reparação do dano ecológico.

Continuando sua atuação diante da Administração Pública, notadamente, nos casos das fundações, agora o Ministério Público passa a ter funções no exercício de curadoria especializada e no plano administrativo para a defesa e proteção do meio ambiente, dos direitos do consumidor e do patrimônio cultural e natural do estado (Lei Orgânica do Ministério Público, Lei Complementarn. 304, de 28 de dezembro de 1982, do Estado de São Paulo).

Sem a necessidade de se criarem funções que reputamos altamente meritórias como a de ombdsman (nos Países Escandinavos), mediateur (França) e de provedor de Justiça (Portugal), é possível utilizarse uma instituição mais antiga, que se renova e se agiliza no sentido de ser autenticamente a Procuradoria da Sociedade.

Amplo é o campo de atuação do Ministério Público também na parte administrativa. Aberto aos anseios da comunidade em que está inserido, poderá requisitar informações da administração e dos próprios e possíveis infratores. Não se trata só e especificamente da propositura de aç̃̃es judiciais, mas do acompanhamento da tomada de providências pelos órgãos administrativos. Agindo nesse momento, o Ministério Público estará presente na fase preventiva do crime ecológico e do dano ambiental.
Não se superpõe um órgão a outro, na administração. Nem se estimulam intervenções indébitas. Mas se proporciona a um órgão socialmente "neutro na defesa da lei" na expressão de Seabra Fagundes 43 , ação como mediador entre as possíveis partes, tentando conseguir uma pronta e eficaz intervenção da administração ambiental.

\section{Nota}

Conferência proferida nas Jornadas sobre Medio Ambiente Y Ordenamiento Jurídico, em Madrid, de 1 a 5 de março de 1983, promoção do Centro Internacional de Formacion en Ciencias Ambientales - CIFCA.

\section{Referências bibliográficas}

1. SIMONET; Doß\&.ique. L'ecologisme. PUF, 1979. p. 45

2. DROIT administratif. S. 1., Éditions Cujas, 1969. p. 88

3. RAMOS, Luis Rodrigues. Instrumentos jurídicos preventivos y repressivos en la protección del medio ambiente. Boletin Informativo del Medio Ambiente, (34) oct./dec. 1981.

4. CANO, Guillermo J. Derecho, politica y administracion ambientales. Buenos Ayres, Ediciones Depalma, 1978, p. 107.

5. MACHADO, Paulo Affonso Leme. Direito ambiental brasileiro. São Paulo, Ed. Revista dos Tribunais, 1982. p. 8-9.

6. Estratégia mundial para la conservacion. UICN - PNUMA WWF (9), 1980.

7. I BENI pubblici. Roma, 1963.

8. PIGRETTI, Eduardo. Politica legal de los recursos naturales. Coperadora de Derecho y Ciencias Sociales, 1975. p. 19.

9. MACHADO, Paulo Affonso Leme. op. cit. p. 256.

10. III SIMPOSIO NAZIONALE SULLA CONSERVAZIONE DELLANATURA. Ricerca scientifica, ricerca giuridica e tutela della persona nell'ambiente in atti. Bari, 1973.

11. ENTERRIA E FERNANDEZ, Garcia de. Curso de derecho administrativo. Madrid, Ed. Civitas, 1981. p. 26.

12. FERRAZ JÚNIOR, Tércio Sampaio. A relação meioffim na teoria geral do direito administrativo. Rev. de Direito Público, 15 (61): 33, jan./mar. 1982.

13. ENTERRIA E FERNANDEZ, Garcia de op. cit. p. 475.

14. WALINE, MArcel. Droit administratif. S. 1. Sirey, 1963. n. 815

15. ESPANHA: Ley de Procedimiento Administrativo, de 17 de julio de 1958, modifica por la de 2 deciembre de 1963; REPÚBLICA FEDERALDA ALEMANHA: Lein. ${ }^{\circ} 59$, de 29 de maio de 1976; PORTUGAL: Decreto-Lei n. 256/A, de 17 de junho de 1977; FRANCCA: Lei n. 587 , de 11 de julho de 1979.

16. SIMPOSIO NACIONAL DA AMAZO̊NIA. Uma oikopolitica para a Amazônia. Brasília, 1979.

17. CROZIER, Michel. La sociéte bloquée. Éditions du Seuil, 1970.

18. ENTERRIA, Garcia de \& RODRIGUES, Fernandez. Curso de derecho administrativo. Madrid Editorial Civitas, 1981. 2v.

19. HAERING, Bernard. Medicina e manipulação. São Paulo, Edições Paulinas, 1977.

20. PRIEUR, Michel. Lagrément des associations de protection de la nature et de l'environnement. Recueil Dallos Sirey. 1978. cahier 23. 
21. GIANINI, Massimo Severo. La tutela degli interessi colletivinei procedimentiamministrativo. Rivista di Direto processuale, 29 (II série) 551: 69, 1974.

22. Intervenção n: 4 colloque de la Sociéte Française pour le droit de l'environnement. Anais sobre o tema "Le contrôle des pollutions industrielles". Publications rériodiques specialisees. Lyon: 91, 1980.

23. La Comission des sites et l'environnement. Revue Juridique de l'environnnement, 403-4, 1981.

24. Ambiènte saggio sui diversi suoi aspetti giuridici. Rivista Trimestrale di Dirito Pubblico, 28, 1973.

25. MACHADO, Paulo Affonso Leme. op. cit. p. 10-11.

26. Metropolization y medio ambiente. In: Estilos de desarollo y medio ambiente en la America Latina. México, Fondo de Cultura Econômica, 1981. p. 32.

27. PELAYO, Manuel Garcia. Las transformaciones del Estado Contemporáneo, Madrid. Alianza Editorial, 1982. p. 167-8.

28. SANTOS, Perseu dos. Teoria ecológica e manejo de ecossistemas terrestres. In: BERTALANFFY, Ludwig Von. Teoria geral dos sistemas. Rev. silvicultura, 16A: 338, 1982.

29. POLITICA e teoria geral do Estado. São Paulo, Saraiva, 1957. p. 233-4.

30. INSTITUICCÕES políticas brasileiras. São Paulo, Livraria José Olympio Editora, 1949. V. 2, p. 204-5.
31. STATO di diritto in transformazione. Milano, Giuffrè Editore, 1973. p. 160-2.

32. BUREAUX et bureaucratie. Presses Universitaires de France, 1967. p. 114.

33. PELAYO, Manuel Garcia. op. cit. p. 119.

34. ELAZAR, Daniel J. Federalismo na América. Diálogo. 16 (1), 1983.

35. Lei de proteção ambiental da Șuécia n: 387 de 1969.

36. GRASSET, Bernard. On ne change pas la sociéte par décret. Paris, 1979. p. 29.

37. INSTITUZIONI di diritto amministrativo. Giuffrè Editore, 1981. p. 11 .

38. CROZIER, Michel. op. cit. p. 104.

39. PELAYO, Manuel Garcia. op. cit. p. 121.

40. PEREIRA, Luiz Carlos Bresser. Estado e subdesenvolvimento industrializado. Ed. Brasiliense, 1977. p. 196.

41. CROZIER, Michel. op. cit. p. 101. 2.

42. Doutrinas de inovação em administração pública; a questão dos valores. In: Inovação na administração pública. Fundação Getúlio Vargas, 1974. p. 21.

43. O Ministério Público e a preservação da ordem jurídica no interesse coletivo. Justitia, 35: 8, 1961. 